\title{
Basque-Spanish bilingual children's expressive and receptive grammatical abilities
}

[Accepted for publication in Linguistic Approaches to Bilingualism]

\author{
Rhiannon M. Anderson ${ }^{1}$ \\ Marcel R. Giezen ${ }^{1}$ \\ Marie Pourquié ${ }^{1}$
}

${ }^{1}$ BCBL. Basque Center on Cognition, Brain and Language

\begin{abstract}
Expressive-receptive gaps in lexical abilities have been documented for bilingual children, but few studies have investigated whether a similar gap is observed at the grammatical level. The current study assessed grammatical abilities through sentence production and comprehension tasks in both languages in 17 Basque-Spanish simultaneous bilingual 6- through 9-year-olds (both languages acquired before three years of age). The children scored lower in Basque than Spanish for sentence production, but no significant differences were found for sentence comprehension. While an expressive-receptive gap was found for both languages, this gap was larger in Basque than in Spanish. Object-verb agreement errors were especially prevalent in Basque production, possibly because verbs in Spanish only agree with the subject. These results demonstrate that expressive-receptive gaps are also observed in bilingual children's grammatical abilities and may vary depending on the structural similarity between the two languages.
\end{abstract}

Key words: bilingual language acquisition; expressive-receptive gap; verb inflection 


\section{Introduction}

Although language development in bilingual children proceeds along the same milestones as for monolingual children, bilingual children have a wide variety of linguistic backgrounds and may not have the same proficiency (i.e. competence) in each language (Genesee \& Nicoladis, 2007; Pearson, Fernández, \& Oller, 1993). Relative differences in proficiency in each language can be modulated by various factors, including variation in relative language input and age of acquisition (Matthews \& Yip, 2011). Because of the variation in linguistic backgrounds and relative language proficiency, it is difficult to say what is considered "typical" language development in bilingual children (e.g., Matthews \& Yip, 2011; Unsworth, 2013). This can, for example, result in difficulties distinguishing whether a child's errors are caused by simply learning a second language or from developmental language disorders such as Specific Language Impairment (Armon-Lotem, de Jong, \& Meir, 2015). Relative performance in each language may also differ depending on the linguistic domain that is being investigated (e.g., lexicon vs. grammar), the structural similarity of the two languages being acquired, and whether expressive or receptive abilities are measured (e.g., Gibson, Peña, \& Bedore, 2014; Müller \& Hulk, 2001).

Specifically, several studies have reported that bilingual children experience more difficulties in language production than in comprehension (e.g., Lesaux, Crosson, Kiefer, \& Pierce, 2010; Pearson et al., 1993; Oller, Pearson, \& Cobo-Lewis, 2007; Swanson, Rosston, Gerber, \& Solari, 2008; Windsor \& Kohnert, 2004). This asymmetry in expressive and receptive language performance is often referred to in the literature as an "expressive-receptive gap" and reflects a larger discrepancy between expressive and receptive language competence as compared to monolingual children (e.g., Gibson, 
Oller, Jarmuowicz, \& Ethington, 2012; Gibson et al., 2014; Yan \& Nicoladis, 2009). Expressive-receptive gaps have been observed in various languages and in children's first language (L1) as well as their second language (L2), although the difference can be more pronounced in one or the other (see Keller, Troesch, \& Grob, 2015 for a review). A better understanding of expressive-receptive gaps in bilingual children can yield valuable insights into production-comprehension asymmetries in language acquisition. Further studies on these gaps can begin to disentangle whether or not the underlying processes and cognitive mechanisms of production and comprehension are shared (e.g., Pickering \& Garrod, 2014). Importantly, most of the studies on expressive-receptive gaps in bilingual children focused on lexical abilities and much less is known about grammatical abilities (Keller et al., 2015). Most of the research on bilinguals' morphosyntactic development has relied on production tasks rather than comprehension tasks (Genesee \& Nicoladis, 2007). The present study therefore investigates the expressive and receptive grammatical abilities of simultaneous Basque-Spanish bilingual children.

\subsection{Expressive-receptive gaps in bilingual lexical development}

From an early age, bilingual children often have smaller expressive vocabularies in each of their languages compared to their monolingual peers (Oller et al., 2007). One possible explanation is that bilingual children may not receive the same amount of input in each language as monolingual children do because language input to a bilingual child is shared between two languages (Pearson, Fernández, Lewedeg, \& Oller, 1997). Indeed, when bilinguals' vocabulary levels are tested conceptually across both languages (i.e., when they are tested to see if they know the words in either of their 
languages) their vocabulary abilities are generally on par with that of monolingual children or even better (Bedore, Peña, Garcia, Cortez; 2005; Hoff et al., 2012; Pearson et al., 1993; Thordardottir, Rothenberg, Rivard, \& Naves, 2006).

Importantly, children's receptive vocabulary levels are generally higher than their expressive vocabulary levels and are less likely to differ from those of monolingual children (e.g., Gibson et al., 2012; Paradis \& Jia, 2017; Yan \& Nicoladis, 2009). Consequently, bilingual children often show a greater gap between their receptive and expressive lexical abilities than monolingual children. Larger gaps have been associated with reduced amounts of language exposure, possibly because of weaker phonological-semantic links (Gibson et al., 2014; Gollan, Montoya, Cera, \& Sandoval, 2008; Keller et al., 2015).

\subsection{Expressive-receptive gaps in bilingual grammatical development}

In the early stages of language learning, lexical and grammatical development are strongly associated (e.g., Bates \& Goodman, 1997; Dale, Dionne, Eley, \& Plomin, 2000; Fenson et al., 1994; Marchman \& Bates, 1994). Studies with bilingual children have demonstrated that the relationship between lexical and grammatical abilities is language-specific and not just a result of general language learning skills (Marchman, Martínez-Sussman, \& Dale, 2004; Kohnert, Kan, \& Conboy, 2010; Parra, Hoff, \& Core, 2011). Bilingual children usually go on to achieve age-adequate competent grammatical abilities in both languages. However, they often make more frequent and qualitatively different errors than monolingual children, and their errors can persist for a longer time (for discussion, see e.g., Genesee \& Nicoladis, 2007).

Although most studies on grammatical development in bilingual children have 
relied on production tasks, there is some evidence for an expressive-receptive gap in bilingual children's grammatical abilities. For example, Chondrogianni and Marinis (2012) found that sequential Turkish-English bilingual children had more difficulties with the production of English tense morphemes than English monolingual children. The bilingual children were nevertheless sensitive to ungrammaticalities resulting from omitted tense morphemes in an online word monitoring task. A similar discrepancy between expressive and receptive performance was observed by Grüter (2005) in the production and comprehension of object clitics by child L2 learners of French.

Importantly, cross-language structural (dis)similarities may differentially impact expressive and receptive language development in bilingual children. For instance, recent studies with monolingual children have reported cross-language variability in the processing of subject-verb agreement related to language specific phonological properties of agreement systems. For example, English-speaking children comprehend singular agreement before plural agreement (Johnson, de Villiers, \& Seymour, 2005), while Spanish-speaking children show the opposite pattern (Pérez-Leroux, 2005). Similarly, French-speaking children show sensitivity to subject-verb agreement in comprehension at an earlier age than, for example, English- or Spanish-speaking children, presumably because additional phonological cues are present in French (Legendre et al., 2013).

In summary, although there is abundant evidence for a lexical expressivereceptive gap in bilingual children in favor of receptive competence, the picture has been less clear for grammatical abilities. Similarly, while expressive-receptive gaps in lexical abilities have been found to be sensitive to variation in language exposure in some studies, it is not clear whether this is also true for grammatical abilities. 
Furthermore, cross-linguistic variation in the development of expressive and receptive grammatical competence may differentially impact expressive-receptive gaps in each of bilingual children's languages. In the present study, we focus on Spanish and Basque, two languages from unrelated language families and with different structural properties, to further investigate the role of language exposure and cross-linguistic structural similarity in bilingual children's grammatical development.

\subsection{Spanish and Basque}

In the Basque Autonomous Community (BAC) of Spain, Spanish and Basque hold a coofficial status. Spanish is very prevalent and there are virtually no monolingual adult speakers of Basque. In the region of Gipuzkoa, where the present study was conducted, $50 \%$ of adults are fully proficient Basque-Spanish bilinguals (Basque Government's Fifth Sociolinguistic Survey, 2011). Almost all parents who speak Basque pass the language on to their children, although it is unknown what the quality of the language input is, as some of these parents are L2 speakers (Barnes and García, 2012). In recent decades there has been an effort to promote the use of Basque, for example, in schools, and approximately half of Basque-speaking young adults learned the language outside of the home. The use of Basque has steadily increased over the years, and $81 \%$ of the population of the BAC believes that it is crucial for children to learn Basque (Basque Government's Fifth Sociolinguistic Survey, 2011).

Basque is a language isolate that forms its own language family. Of particular interest for the present study is that Basque and Spanish have several different grammatical properties. For example, Basque is a Subject-Object-Verb language that has ergative morphology, whereas Spanish is a Subject-Verb-Object language that has 
accusative morphology. In addition, Basque has polypersonal agreement and auxiliary verbs agree with both the subject and the object, whereas Spanish has monopersonal agreement and verbs agree with only the subject. Furthermore, Spanish uses object clitics, like in English (e.g., 'le da el libro' he gives him the book), whereas Basque does not use clitics and exhibits rich inflection (e.g. 'liburua ematen dio' he gives him the book, where the auxiliary 'dio' encodes agreement with a singular ergative subject, a singular absolutive direct object, and a singular dative indirect object). Both Basque and Spanish are pro-drop languages and subject pronouns can be omitted from the sentence. This feature is particularly relevant when assessing the comprehension of verb agreement (e.g., Culbertson \& Legendre, 2014; Pourquié, 2013). Examples of the different verb agreement forms in Spanish and Basque are provided in Table 1.

Table 1. Verb agreement forms in Basque and Spanish.

\begin{tabular}{|c|c|c|}
\hline Grammatical form & Basque & Spanish \\
\hline \multirow[t]{2}{*}{ Intransitive $3^{\text {SGS }}$} & haurra handitzen da & el niño crece \\
\hline & 'the child grows' & 'the child grows' \\
\hline \multirow[t]{2}{*}{ Intransitive $3^{\text {PLS }}$} & haurrak handitzen dira & los niños crecen \\
\hline & 'the children grow' & 'the children grow' \\
\hline \multirow[t]{2}{*}{ Transitive $3^{\text {SGS }}$} & haurrak lorea usaintzen du & el niño huele la flor \\
\hline & 'the child smells the flower' & 'the child smells the flower' \\
\hline \multirow[t]{2}{*}{ Transitive $3^{\text {PLS }}$} & haurrek lorea usaintzen dute & los niños huelen la flor \\
\hline & 'the children smell the flower' & 'the children smell the flower' \\
\hline \multirow[t]{2}{*}{ Transitive $3^{\text {PLDO }}$} & haurrak loreak usaintzen ditu & el niño huele dos flores \\
\hline & 'the child smells two flowers' & 'the child smells two flowers' \\
\hline Ditransitive $3^{\text {SGIO }}$ & haurrak txakurrari pilota botatzen dio & el niño lanza la pelota al perro \\
\hline
\end{tabular}




\begin{tabular}{l|cc} 
Ditransitive 3 & $\begin{array}{c}\text { 'the child throws the ball to the dog' } \\
\text { haurrak txakurreri pilota botatzen die }\end{array}$ & 'the child throws the ball to the dog' \\
'the child throws the ball to the dogs' & 'the child throws the ball to the dogs' \\
\hline
\end{tabular}

Note. 3 SGS $=$ third singular subject; 3 PLS $=$ third plural subject; 3PLDO $=$ third plural direct

object; $3 \mathrm{SGIO}=$ third singular indirect object; $3 \mathrm{PLIO}=$ third plural indirect object

Monolingual Basque children have acquired most morphosyntactic forms around five years of age (Soto Valle \& Aguado Alonso, 2015). Case morphology in Basque, especially in the singular form, is acquired relatively early between two and three years of age (Barreña 1995; García et al. 2007; Larrañaga 1994). Regarding verb morphology, Ezeizabarrena and Larrañaga (1996) found that children acquired subject agreement before object agreement. Basque children acquire the polypersonal agreement inflectional system gradually. Specifically, absolutive agreement is acquired before ergative inflection, while dative inflection is acquired last (Austin, 2009).

Variation in language exposure has been shown to influence lexical and grammatical development in Basque-Spanish bilingual children. For example, Barnes and García (2012) found that toddlers with a high level of exposure to Basque had a higher proportion of verbs in their vocabulary compared to toddlers learning other languages (such as Galician and Catalan), which may further impact their syntactic acquisition (Meisel, 2012).

In addition, the acquisition of grammatical inflections in Basque may be delayed in young Basque-Spanish bilingual children depending on their level of bilingualism (Austin, 2009; Ezeizabarrena, 2012). For example, Ezeizabarrena, Manterola, and Beloki (2009) found that young sequential learners of L2 Basque with L1 Spanish tended to overuse the absolutive case, exhibited difficulty with dative case, and 
displayed a slower pace in acquiring case morphology and argument-verb agreement markings compared to bilingual children with L1 Basque. Furthermore, Austin (2009) found that toddlers in bilingual homes produced more root infinitives in Basque than Basque monolingual children, likely because they were less exposed to Basque. Specifically, she found that number and tense were acquired later by the bilingual children.

Importantly, there is also some evidence that cross-linguistic similarities across Spanish and Basque may influence grammatical development in bilingual BasqueSpanish children. For example, Basque and Spanish have two copula verbs that are similar across the two languages in their grammatical functions. Spanish 'ser' and Basque counterpart 'izan' are used for permanent or intrinsic characteristics, and Spanish 'estar' and Basque 'egon' for temporary states. Larrañaga and Guijarro-Fuentes (2012) studied these verbs in school-aged children with varying amounts of Basque exposure. Their results showed that even Spanish-dominant children did not make errors with either of the copula verbs in Basque. This suggests that shared features across the two languages may be easier to acquire for Basque-Spanish bilingual children, and may reflect transfer between the languages. Cross-linguistic influence in bilingual children might thus depend on whether underlying linguistic structures are shared between the two languages (Nicoladis, Rose, \& Foursha-Stevenson, 2010). Specifically, shared grammatical structures between languages may be less prone to errors in bilingual acquisition than unshared structures. For example, bilingual Basque-Spanish children might make more errors in object-verb agreement than subject-verb agreement in Basque, because verbs do not agree with objects in Spanish, while verbs agree with subjects in both languages. 


\subsection{The current study}

In the current study, we investigated whether simultaneous Spanish-Basque bilingual children show an expressive-receptive gap in grammatical abilities, and whether the relative exposure to each language and/or cross-linguistic structural similarity impacts their performance on grammatical production and comprehension tasks. First, we expected children to perform better in Spanish than Basque on all tasks, due to the majority status of Spanish in the region and the complex morphological system of Basque as compared to Spanish. Second, we expected children to show less difficulty in Basque comprehension than Basque production based on previous studies suggesting lower performance in expressive tasks compared to receptive tasks in other languages. These first two outcomes together would be consistent with an expressive-receptive gap in grammatical abilities in Basque, but possibly not in Spanish, as the majority language. Third, we predicted that children's performance in Basque production would depend on the relative amount of exposure to that language (as reported by parents). Fourth, considering Spanish and Basque language typology, we expected children to exhibit more difficulties with inflectional forms in Basque that are not shared with Spanish than with forms that are shared between the two languages and that possibly allow for cross-linguistic transfer.

\section{Methods}

\subsection{Participants}

Twenty-three Basque-Spanish simultaneous bilingual children, ages six through nine, participated in this study at the Basque Center on Cognition, Brain and Language (BCBL). Although not all children in the BAC speak Basque at home, the reported age 
of acquisition of Basque was three years or younger for all children and they were therefore considered simultaneous bilinguals. They were tested at an age when they presumably could have had enough exposure to Basque at school to complete the grammatical production tasks of the study. The children were recruited from the San Sebastián area in the Gipuzkoa province. Six children were excluded from analyses for different reasons, including an incomplete dataset $(n=1)$, technical failure $(n=1)$, suspected learning disorder $(n=1)$, and insufficient level of Basque to complete the sentence production task in that language $(n=3)$. This resulted in a final group of 17 children (seven females; mean age $=7.9$ years; $S D=1.1$ years; range $=6.1-9.8$ years). None of the children had a diagnosis of a learning disorder, cognitive difficulties, or hearing impairments.

At the time of the study, parents reported that the children were on average exposed to Basque $57 \%$ of the time $(S D=17 \%)$ and Spanish $36 \%$ of the time $(S D=$ 17\%). Furthermore, for 16 children at least one parent used Basque at home. Based on their age of acquisition, all children can be considered simultaneous bilinguals.

\subsection{Materials}

\subsubsection{Parent questionnaire}

Information on age of acquisition, proficiency, language usage of members of the child's family, and frequency of exposure and use of each language was obtained through the BCBL's language background questionnaire completed by parents. Specifically, parents were asked to list the average percentage of time the child listens to, speaks in, reads in, and writes in each language. Parent questionnaires can be a quick and efficient way to obtain information on a children's language abilities and have been 
shown to be a significant predictor of grammatical abilities in bilingual children (e.g., Gutiérrez-Clellen \& Krieter, 2003).

\subsubsection{BEST}

The BEST (Basque English Spanish Test; de Bruin, Carreiras, \& Duñabeitia, 2017) is an untimed picture naming task used at the BCBL. It was used to assess the child's expressive vocabulary knowledge in Spanish and Basque. The BEST consists of 65 drawings of objects in a booklet. The child is presented with each picture and asked to name the item in the target language. If the child named the object in the nontarget language or was unsure what was depicted, the researcher prompted the child for the word in the target language or by describing the object.

\subsection{3 fLEX}

The fLEX tool (from the words 'inFlectional' and 'LEXical') has been developed by Pourquié (2015) to assess lexical and inflectional processing in Spanish, Basque and French. In the lexical domain, the fLEX tool evaluates object naming and action naming abilities. In the grammatical domain, the focus of the present study, the test evaluates children's knowledge of argument structure and verbal inflection in sentence production and comprehension. In addition, the fLEX evaluates the child's use of prepositions and grammatical case.

The fLEX contains 160 items across five different untimed tasks. The first two tasks assess expressive lexical knowledge of the target nouns and verbs used in the grammatical components of the fLEX (object naming and action naming, each 30 items). The third task assesses the child's ability to form full sentences with present 
tense verbs associated with various argument structure types (sentence production, including 10 intransitive, 15 transitive and 10 ditransitive target verbs). The fourth task requires children to listen to 35 sentences with grammatical inflections and different argument structure types (sentence comprehension, including 10 intransitive, 15 transitive and 10 ditransitive verbs). Their task is to select the picture depicting the event described by the sentence among four pictures. The other pictures mismatch with the presented verb form in lexical information, inflectional information (number), or both. For example, for the target verb 'corre' (he runs), 'nada' (he swims) would function as a lexical distractor, 'corren' (they run) as an inflectional distractor, and 'nadan' (they swim) as a mixed distractor. Items in the sentence production and sentence comprehension task are classified in seven different categories according to the different inflectional forms used in Basque (see Table 1): intransitive (singular or plural subjects), transitive (singular or plural subjects), transitive plural object, ditransitive singular indirect object, or ditransitive plural indirect object.

The final task in the fLEX assesses the child's ability to form prepositional phrases, which are expressed as case markings in Basque and free morphemes in Spanish (prepositional phrase production, 30 items). The fLEX is presented on an Android tablet. Instructions are available in each of the three target languages, and audio recordings of the child's responses in the four production tasks are automatically stored on the tablet. Each task begins with three examples. For the present study, we will focus on results from the sentence production and comprehension task of the fLEX. 


\subsection{Procedure}

Children were tested in one-hour sessions on two separate occasions at least a week apart (one session for each language, counterbalanced across children). The sessions took place in a quiet testing room at the BCBL. At the beginning of each session, the researcher briefly explained the tasks and purpose of the study to the child and parent and asked the parent to fill out the consent form and language background questionnaire. Next, the BEST and fLEX were administered in this order.

The aim of the sentence production task in the fLEX is to examine the use of verbs within a sentential context and not on lexical retrieval. Therefore, the research assistant prompted the child with the correct word if the child did not know a critical word to complete the sentence. Furthermore, the research assistant encouraged the children to use the present tense in place of the present progressive as use of the present tense forces the production of seven different inflected forms in Basque, while the use of the progressive form does not offer the same variation in inflected forms. In the sentence comprehension task, auditory sentences were presented and the child had to select the picture that depicted the event described by each sentence by tapping on one of the four pictures. Responses were automatically recorded by the tablet.

\subsection{Error coding}

The BEST was scored by the researcher during the session using a scoresheet with target answers. The final score consisted of the proportion correct out of the total number of presented items (65).

The sentence production task in Spanish was transcribed and coded by one of the authors and checked by a native Basque-Spanish bilingual research assistant. 
Basque productions were transcribed and coded by a Basque-speaking research assistant and checked by another native Basque speaker. Responses were scored as correct if the child produced a contextually appropriate verb with the same number of expected arguments. For example, for the target sentence 'el niño lanza la pelota al perro' (the boy throws the ball to the dog), the sentence 'el niño tira la pelota al perro' (the boy passes the ball to the dog) would be scored as correct, but 'el niño juega con el perro' (the boy plays with the dog) would be incorrect because an intransitive verb is used instead of the target ditransitive verb. In addition, all arguments of the sentence had to be grammatically present to be a correct response. For example, 'el niño lanza la pelota' (the boy throws the ball) would be incorrect because the recipient, 'al perro' (to the dog) is missing from the sentence. As both Basque and Spanish are pro-drop languages, omission of the subject argument was not considered an error if it was grammatically marked on the verb. For example, both 'lanza la pelota al perro' (throws the ball to the $d o g$ ) and 'el niño le lanza la pelota' (the boy throws him the ball) were considered correct responses. Although children were encouraged to use the present tense as opposed to the present progressive form, utterances with the progressive form were scored as correct. The main reason is that these forms are grammatically correct, although it is possible that some children used this form as an avoidance strategy of verb agreement. Responses in the sentence comprehension task were automatically scored for accuracy and type of error (lexical, inflectional or mixed) by the fLEX software. 


\section{Results}

Because of the small sample size and use of percentage correct scores, statistical analyses were performed using non-parametric rank-based tests in the statistical software program $R$ v.3.5.0 (R Development Core Team, 2018). Boxplots for both languages in production and comprehension on the fLEX are shown in Figure 1.

\subsection{Expressive-receptive gap}

Children's mean expressive vocabulary score (BEST) was higher in Spanish $(M=$ $92.3 \%, S D=8.3 \%)$ than in Basque $(M=81.0 \%, S D=12.3 \%), Z=2.72, p<.01, r=.66$. The results from the sentence production and comprehension task were analyzed as a 2 x 2 factorial design with Language (Spanish, Basque) and Task (sentence production, sentence comprehension) as within-subject factors. For this analysis we used the nparLD package v.2.1 (Noguchi et al., 2012; see also Feys, 2016) and report the ANOVA-type statistic (ATS). We found significant main effects of Language (ATS = $11.78, p<.001)$ and Task $(A T S=37.64, p<.001)$, reflecting overall higher accuracy in Spanish than Basque and higher accuracy in sentence comprehension than production. Importantly, these main effects were qualified by a significant Language $\mathrm{x}$ Task interaction $(A T S=6.79, p<.01)$. Posthoc pairwise Wilcoxon signed rank comparisons showed that children were less accurate in sentence production than in comprehension in Basque $(Z=-3.60, p<.001, r=-.87)$ as well as Spanish $(Z=-1.97, p<.05, r=-.48)$, demonstrating an expressive-receptive gap in grammatical abilities in both languages (see Figure 1). Sentence comprehension scores for Spanish $(M=95.1 \%, S D=8.6 \%)$ and Basque $(M=95.3 \%, S D=4.2 \%)$ did not significantly differ $(Z=-.34, p=.73, r=-$ .08). In contrast, however, sentence production scores were significantly higher in 
Spanish $(M=88.9 \%, S D=10.6 \%)$ than in Basque $(M=77.3 \%, S D=16 \%), Z=2.98, p$ $<.01, r=.72$. Together, these results indicate a larger expressive-receptive gap in grammatical abilities for Basque $(M=18.3 \%, S D=15.1 \%)$ than Spanish $(M=6 \%, S D=$ $11.3 \%)$

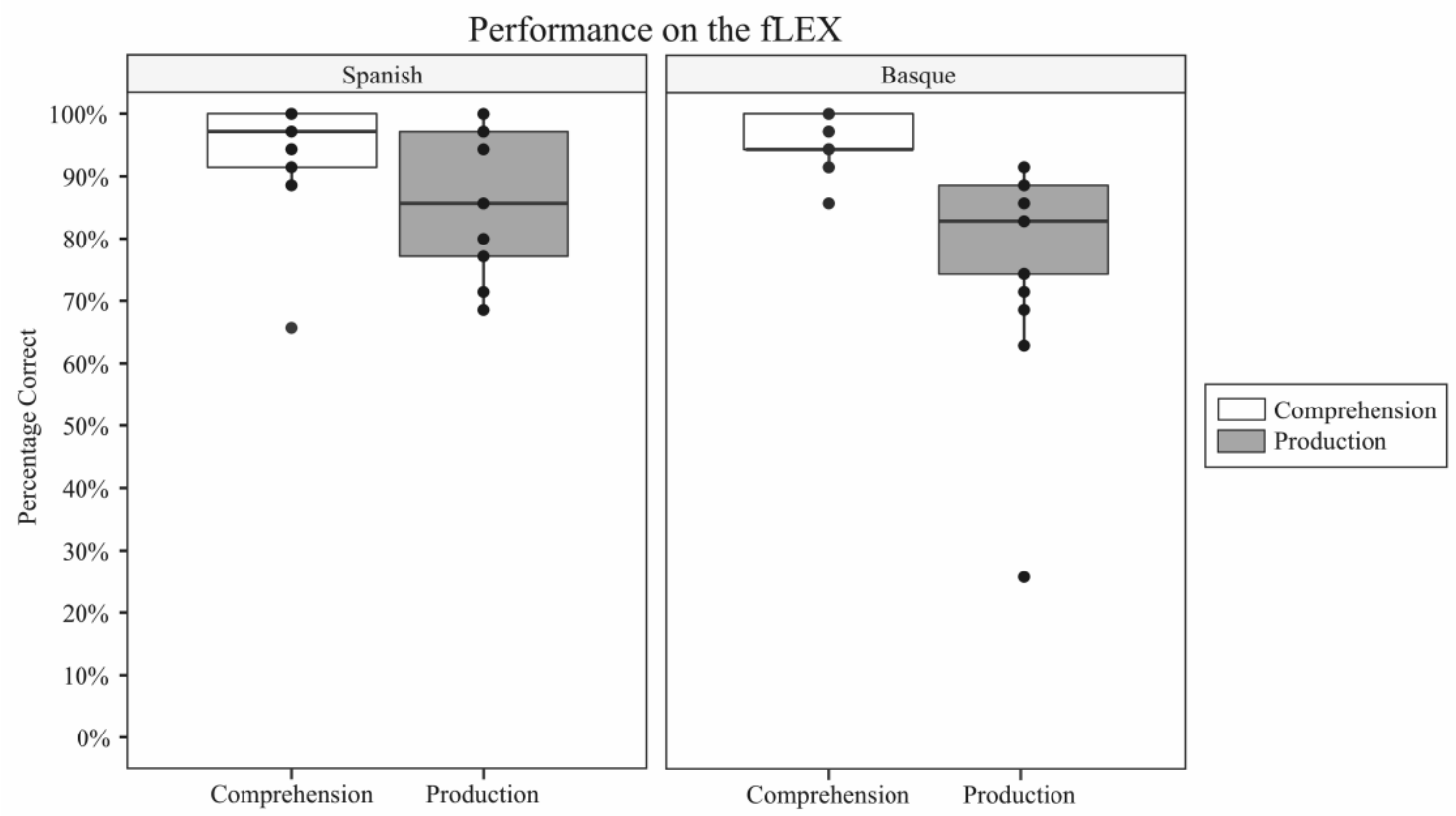

Figure 1. Percentage correct scores in Spanish and Basque on the sentence comprehension and production tasks of the fLEX.

\subsection{Correlations with age and language exposure}

To investigate the impact of age and language exposure on lexical and grammatical abilities of Basque-Spanish children, we conducted a Spearman correlation analysis between age, percentage of language exposure, expressive vocabulary, and sentence production and comprehension scores in each language (see Table 2 and Table 3 for Spanish and Basque, respectively). For Spanish, expressive vocabulary was correlated with percentage of exposure to $\operatorname{Spanish}(R=.51, p<.05)$. For Basque, age was positively correlated with expressive vocabulary $(R=.62, p<.01)$, sentence production 
$(R=.58, p<.05)$, and sentence comprehension $(R=.51, p<.05)$. Furthermore, sentence production was positively correlated with sentence comprehension $(R=.51, p$ $<.05)$. However, this correlation was no longer significant after statistically controlling for age in the analysis $\left(R_{p}=.31, p=.25\right)$.

Table 2. Spearman correlations between age, language exposure, expressive vocabulary, sentence production and sentence comprehension in Spanish.

\begin{tabular}{|c|c|c|c|c|c|}
\hline & age & $\%$ exposure & BEST & PROD & COMP \\
\hline age & -- & -.32 & .30 & .4 & .35 \\
\hline$\%$ exposure & & -- & $.51^{*}$ & -.16 & -.15 \\
\hline BEST & & & -- & .06 & .10 \\
\hline PROD & & & & -- & .20 \\
\hline COMP & & & & & -- \\
\hline
\end{tabular}

Note. $\mathrm{PROD}=$ sentence production, $\mathrm{COMP}=$ sentence comprehension

$*=\mathrm{p} \leq .05$

Table 3. Spearman correlations between age, language exposure, expressive vocabulary, sentence production and sentence comprehension in Basque.

\begin{tabular}{|c|c|c|c|c|c|}
\hline & age & $\%$ exposure & BEST & PROD & COMP \\
\hline age & -- & .27 & $.62 * *$ & $.58 *$ & $.51 *$ \\
\hline$\%$ exposure & & -- & .08 & .33 & -.10 \\
\hline BEST & & & -- & .31 & .08 \\
\hline PROD & & & & -- & $.51^{*}$ \\
\hline COMP & & & & & -- \\
\hline
\end{tabular}


Note. $\mathrm{PROD}=$ sentence production, $\mathrm{COMP}=$ sentence comprehension

$*=\mathrm{p} \leq .05 * *=\mathrm{p} \leq .01$

\subsection{Effects of argument structure and cross-linguistic similarity}

To investigate the impact of argument structure and cross-linguistic similarity on the grammatical abilities of Basque-Spanish bilingual children, we conducted an in-depth analysis of errors in the sentence comprehension task and the sentence production task. Mean error rates for both languages and tasks are shown in Table 4.

Errors in the sentence comprehension task were automatically coded by the tablet software, which recorded if the incorrect response was a lexical error (i.e., distractor involving a nontarget verb), an inflectional error (i.e., distractor involving the target verb but mismatching in number), or a mixed error (i.e., a nontarget verb mismatching in number).

Table 4. Distribution of error rates in sentence production and comprehension in Basque and Spanish

\begin{tabular}{|c|c|c|c|c|}
\hline \multirow[b]{2}{*}{ Sentence Type } & \multicolumn{2}{|c|}{ Basque } & \multicolumn{2}{|c|}{ Spanish } \\
\hline & PROD & COMP & PROD & COMP \\
\hline Intransitive singular subject & $20 \%$ & $4.7 \%$ & $9.4 \%$ & $2.4 \%$ \\
\hline Intransitive plural subject & $25.9 \%$ & $2.4 \%$ & $8.2 \%$ & $3.5 \%$ \\
\hline Transitive singular subject & $15.3 \%$ & $1.2 \%$ & $10.6 \%$ & $1.2 \%$ \\
\hline Transitive plural subject & $12.9 \%$ & $3.5 \%$ & $12.9 \%$ & $2.4 \%$ \\
\hline Transitive plural object* ${ }^{*}$ & $21.2 \%$ & $4.7 \%$ & $8.2 \%$ & $5.9 \%$ \\
\hline
\end{tabular}




\begin{tabular}{l|cccc}
\cline { 2 - 4 } Ditransitive* & $22.4 \%$ & $7.1 \%$ & $10.6 \%$ & $8.2 \%$ \\
Ditransitive plural indirect object* & $43.8 \%$ & $8.2 \%$ & $17.6 \%$ & $8.2 \%$ \\
\hline Note. PROD = sentence production, COMP = sentence comprehension \\
* clitics in Spanish comprehension
\end{tabular}

Bilingual children in the current study made relatively few errors in the sentence comprehension task in either language ( $n=27$ for Basque and $n=29$ for Spanish), with very few mixed errors ( $n=4$ across both languages), that is, erroneous selection of the distractor mismatching in target verb as well as number. In Basque, most errors were inflectional errors $(n=17)$, followed by lexical errors $(n=8)$, while in Spanish lexical and inflectional errors were equally distributed ( $n=13$ and $n=14$, respectively).

However, it should be noted that there was no significant difference in the distribution of lexical and inflectional errors across the two languages $\left(\chi^{2}(1)=.82, p=.37\right)$. Table 4 further shows that incorrect responses in sentence comprehension were relatively uniformly distributed across most sentence types, except for sentences with ditransitive verbs that accounted for 55\% (16/29) of the errors in Spanish and 48\% (13/27) in Basque.

We first analyzed the impact of argument structure on children's accuracy in sentence production by comparing error rates for intransitive, transitive and ditransitive verbs. Non-parametric Friedman tests yielded a significant effect of argument structure for Basque $\left(\right.$ Friedman $\left.\chi^{2}(2)=6.91, p<.05\right)$, but not for Spanish $\left(\right.$ Friedman $\chi^{2}(2)=1.32$, $p=.52)$. Post-hoc pairwise comparisons conducted using the PMCMR package v.4.3 (Pohlert, 2016) showed significantly higher error rates for ditransitive verbs than transitive verbs $(p<.05)$, but no difference between ditransitive verbs and intransitive 
verbs $(p=.27)$, or intransitive verbs and transitive verbs $(p=.56)$. These results suggest that sentences with ditransitive verbs in Basque were relatively difficult for the bilingual children. Most of their errors in these sentences were agreement errors (production of incorrectly inflected verb forms) in Basque (23 out of 54 errors; 43\%), while most errors with ditransitive verbs in Spanish consisted of argument structure errors (omission of the indirect object) in Spanish (14 out of 24 errors; 58\%).

Second, we examined the role of cross-linguistic structural similarity in sentence production. Because of its polypersonal agreement, Basque has more agreement morphemes than Spanish. Three of these agreement forms were included in the fLEX: 'ditu' marks the plural object of a transitive verb, 'dio' marks a singular indirect object of a ditransitive verb, and 'die' marks a plural indirect object of a ditransitive verb (see Table 1). We expected that these Basque verb forms would be vulnerable in bilingual children's grammatical processing because of the lack of shared structural properties with Spanish. Visual inspection of Table 3 suggests that mean error rates for these forms were indeed relatively high in Basque production (range: $21 \%-44 \%$ ) and comprehension (range: 5\%-8\%) compared to the other Basque forms. However, statistical comparison of mean error rates across cross-linguistically "shared" (first four rows in Table 4) and "unique" (last three rows in Table 4) agreement forms in Basque did not reach significance for either sentence production $(Z=-.161, p=.11, r=-.39)$ or comprehension $(Z=-1.85, p=.06, r=-.44)$.

\section{Discussion}

The current study investigated the expressive and receptive grammatical abilities of Basque-Spanish bilingual children. As predicted, most children performed very well in 
Spanish in both sentence comprehension and production. Even though in most families at least one of the parents spoke Basque at home and the children were currently on average more exposed to Basque than Spanish, expressive vocabulary and sentence production scores were significantly higher in Spanish than in Basque. This may be explained by the fact that Basque holds a minority status and was acquired later than Spanish by many children.

In contrast, sentence comprehension scores were similar in the two languages. Indeed, a grammatical expressive-receptive gap was found in both languages, but this gap was significantly larger for Basque than Spanish. Error analyses further revealed that sentences with ditransitive verbs and agreement forms that are not shared between Spanish and Basque elicited more errors in Basque, particularly in production.

However, it should be noted that this difference failed to reach statistical significance.

\subsection{Expressive-receptive grammatical gap in Basque-Spanish bilingual children}

Although there is robust evidence for an expressive-receptive gap in lexical abilities in bilingual children (for discussion, see e.g. Keller et al., 2015; Yan \& Nicoladis, 2009), it has been less clear if a similar gap can be observed in the grammatical abilities of bilingual children of different languages (e.g., Chondrogianni \& Marinis, 2012; Grüter, 2005; Keller et al., 2015). Our findings demonstrate that Basque-Spanish bilingual children indeed show an expressive-receptive gap at the grammatical level. Testing bilingual children in one modality only may therefore not accurately reflect bilingual children's overall competency in each language. More specifically, testing only their comprehension abilities may overestimate their competency, while testing only their production abilities may underestimate their competency in grammatical structures they 
can comprehend, but not yet consistently produce. In addition, bilingual children's production abilities may be more sensitive to variation in language exposure than their comprehension abilities (Keller et al., 2015).

\subsection{The role of language exposure}

Previous studies that examined the role of language exposure on differences in expressive and receptive performance in bilingual children have yielded mixed results (Gibson et al., 2014; Keller et al., 2015; Oller et al., 2007). In the current study, exposure to Spanish as reported by parents correlated significantly with Spanish receptive vocabulary, but no correlations were found between language exposure and grammatical abilities for either of the two languages. The small sample size in the current study and reliance on parent report measures of language exposure (at the risk of over- or underestimation) may explain why we did not find evidence for effects of relative language exposure on children's grammatical abilities. In addition, language exposure might be further defined in terms of language use in the family, at school and with other people, which may more accurately reflect actual exposure to each language and relate more strongly to bilingual children's grammatical development (Keller et al., 2015; Talking Pupils, 2013).

Despite the high rates of exposure to Basque, all children performed very well in Spanish. This is consistent with a study on bilingual children in Wales, a bilingual community that shares many characteristics with the Basque Autonomous Community (Gathercole \& Thomas, 2009). The authors of that study examined bilingual children's English and Welsh language abilities based on the home and school environment of the children. They found that by age seven (and older) all children performed equally well 
on measures of their English skills, even those who only spoke Welsh at both home and school. Both that study and the current study thus suggest that children will learn the majority language without difficulty, regardless of the language(s) spoken at home. In contrast, the minority language might be vulnerable despite considerable exposure at home. This suggests that the sociolinguistic context of the two languages can have a profound impact on bilingual children's grammatical development.

\subsection{The role of language similarity}

In the current study, we compared grammatical performance of bilingual children in two typologically distinct languages with structurally different sentence-level verb agreement, allowing for a more in-depth look at children's performance with grammatical forms that are not shared across the two languages. Indeed, we found a non-significant trend towards higher error rates for polypersonal agreement forms in Basque that Spanish verbs do not distinguish between. That is, verbal morphology structures that are not shared between the two languages might show a protracted development in Basque-Spanish bilingual children (see also Soto Valle \& Aguado Alonso, 2015).

One possible explanation for this slower development would be that children compensated for the complexity of case-marking in Basque by omitting argument markings for indirect objects, which might be considered a form of cross-linguistic transfer between Spanish and Basque. However, while most errors in Spanish ditransitive sentences involved argument omission, most errors in Basque involved incorrect inflections (e.g., using singular dative 'dio' instead of plural dative 'die'), suggesting a limited role for transfer. However, we cannot rule out that stronger 
evidence for transfer might have been found if younger children had been tested (cf. Müller \& Hulk, 2001). At the same time, it should be noted that there is evidence of cross-linguistic influence in bilingual children until the age of seven years (e.g., dative case marking in German-Italian children; Scherger, 2016) ${ }^{1}$. Furthermore, grammatical structures that differ at the (morpho)syntactic level between Spanish and Basque also reveal distinct patterns of language processing in non-native adult bilinguals (e.g., Laka, Santesteban, Erdocia, \& Zawiszewski, 2012) and, for example, in bilingual adults with aphasia (Munarriz, Ezeizabarrena, \& Gutierrez-Mangado, 2016).

Regardless of the underlying explanation, assessing bilingual children's performance on grammatical structures that are shared or not shared between the two languages is essential to accurately characterize their grammatical abilities, and identify potentially vulnerable areas in bilingual sentence processing. In addition, although this remains speculative based on the current results, cross-language structural differences may disproportionately affect grammatical production more than comprehension, and thus contribute to the expressive-receptive gap in bilingual children.

\subsection{Theoretical implications for studying production and comprehension}

Evidence that bilingual children show a gap between expressive and receptive performance at the lexical and grammatical level has important implications for our understanding of relationships between language production and comprehension in typically and atypically developing children. Our findings demonstrate better grammatical comprehension than production abilities in Basque-Spanish bilingual

\footnotetext{
${ }^{1}$ We thank an anonymous reviewer for this suggestion
} 
children. Grammatical production in bilingual children thus appears to be more variable than their comprehension and may further be more susceptible to cross-linguistic influence. In addition, bilingual children's production difficulties may be modulated by slower lexical access, possibly because of reduced frequency of use of each language (e.g., Gibson et al., 2014; Yan \& Nicoladis, 2009).

Studies of bilingual children's expressive-receptive gap in lexical and grammatical development therefore provide a critical test case for theoretical and computational models of language processing and acquisition with a shared architecture for production and comprehension (e.g., Chater, McCauley, \& Christiansen, 2016; Pickering \& Garrod, 2014). Specifically, these theories should be able to account for the fact that language production in bilingual children is particularly vulnerable and variable across languages. A better understanding of the factors that mediate asymmetrical patterns in bilingual children's expressive and receptive language processing will thus provide valuable insights into the cognitive and linguistic mechanisms underlying language production and comprehension.

\subsection{Practical implications}

Studies on language development in typical bilingual Basque-speaking school-aged children can be used as a benchmark when screening for language impairment in bilingual children. In this context, the findings from the current study contribute data from experimentally-controlled sentence production and comprehension tasks to the existing literature on the grammatical abilities and error patterns of typically developing Basque-Spanish bilingual children (e.g., Austin, 2009; Barreña \& Almgren 2012; Ezeizabarrena, 2012, Soto Valle \& Aguado Alonso, 2015). This is especially important 
because child language disorders such as Specific Language Impairment (SLI) manifest themselves differently in languages with different typological properties (Leonard, 2014). Each language's grammar must therefore be carefully considered when assessing the grammatical abilities of bilingual children suspected of a developmental language disorder. For example, in the current study typically developing bilingual children made more inflectional errors in Basque than in Spanish (cf. Austin, 2009). In contrast, children with SLI would likely produce inflectional errors in both languages (Kohnert, 2010; Paradis, Crago, \& Genesee, 2005).

Furthermore, given that the bilingual children in the current study performed better in sentence comprehension than production, it would be valuable to assess bilingual children with SLI using similar tasks across different languages to determine whether grammatical production and comprehension are both impaired in these children (e.g., Blom, Vasić, \& de Jong, 2014). It is possible that in contrast to many bilingual children, children with SLI also show difficulty in comprehension, especially if relevant grammatical contrasts are marked by easy-to-miss phonological changes, such as 'huele' (he smells) vs. 'huelen' (they smell) in Spanish (Leonard, Miller, Owen, 2000). Assessment of bilingual children in both of their languages is crucial to test such hypotheses when morphophonological properties differ across the languages.

\section{Conclusion}

In conclusion, our results provide evidence for an expressive-receptive gap in the grammatical abilities of school-aged Basque-Spanish bilingual children. They further suggest that typological differences between the languages might contribute to bilingual children's strengths and weaknesses in sentence processing. Studies that assess both 
language production and comprehension in each of bilingual children's languages, while considering language-specific grammatical properties, are essential for an accurate and complete characterization of the grammatical development of bilingual children. Moreover, such studies hold promise to yield unique insights into the commonalities and differences in the mechanisms and processes underlying language production and comprehension.

\section{Acknowledgements}

The authors acknowledge financial support from the Spanish Ministry of Economy and Competitiveness, through the Severo Ochoa Programme for Centres/Units of Excellence in R\&D (SEV-2015-490). We thank Joana Izurieta, Oihana Vadillo, Larraitz López, and the Neure Clinic for their help in coordinating this study. We also thank research assistants Sara Martínez, Amets Esnal, Ainhoa Eguiguren, Elena Aguirrebengoa, Alazne Alegre, and Maider Ávila for helping with the testing of participants and data coding. 


\section{References}

Armon-Lotem, S., de Jong, J., Meir, N. (2015). Assessing multilingual children:

Disentangling bilingualism from language impairment (Vol. 13). Multilingual matters.

Austin, J. (2009). Delay, interference and bilingual development: The acquisition of verbal morphology in children learning Basque and Spanish. International Journal of Bilingualism, 13(4), 447-479.

Barnes, J., \& García, I. (2012). Vocabulary growth and composition in monolingual and bilingual Basque infants and toddlers. International Journal of Bilingualism, 17(3), 357-374.

Barreña, A. (1995). Gramatikaren jabekuntzagarapena eta haur euskaldunak. Bilbao: Servicio Editorial de la Universidad del Pais Vasco.

Barreña, A., \& Almgren, M. (2012). Object-verb and verb-object in Basque and Spanish monolinguals and bilinguals. International Journal of Bilingualism, 17(3), 337-356.

Basque Government. (2011). Fifth Sociolinguistic Survey: The Basque Country. Vitoria-Gasteiz: Servicio de Publicaciones del Gobierno Vasco.

Bates, E., \& Goodman, J. C. (1997). On the inseparability of grammar and the lexicon: Evidence from acquisition, aphasia and real-time processing. Language and cognitive Processes, 12(5-6), 507-584.

Bedore, L. M., Peña, E. D., Garcia, M., \& Cortez, C. (2005). Conceptual versus monolingual scoring: when does it make a difference?. Language, Speech, and Hearing Services in Schools, 36(3), 188-200. 
Blom, E., Vasić, N., \& de Jong, J. (2014). Production and processing of subject-verb agreement in monolingual Dutch children with specific language impairment. Journal of Speech, Language, and Hearing Research, 57(3), 952965.

de Bruin, A., Carreiras, M., \& Duñabeitia, J. A. (2017). The BEST dataset of language proficiency. Frontiers in Psychology, 8(522).

Department of Education, Language Policy and Culture of the Basque Government and Sociolinguistics cluster (2013). Talking Pupils: The Arrue Project 2011. Retrieved from http://www.soziolinguistika.eus/arrue

Chater, N., McCauley, S. M., \& Christiansen, M. H. (2016). Language as skill: Intertwining comprehension and production. Journal of Memory and Language, 89, 244-254.

Chondrogianni, V., \& Marinis, T. (2012). Production and processing asymmetries in the acquisition of tense morphology by sequential bilingual children. Bilingualism: Language and Cognition, 15(01), 5-21.

Culbertson, J., \& Legendre, G. (2014). Prefixal agreement and impersonal 'il'in Spoken French: Experimental evidence. Journal of French Language Studies, 24(01), 83-105.

Dale, P. S., Dionne, G., Eley, T. C., \& Plomin, R. (2000). Lexical and grammatical development: A behavioural genetic perspective. Journal of Child Language, 27(03), 619-642.

Ezeizabarrena, M. J. (2012). The (in)consistent ergative marking in early Basque: L1 vs. child L2. Lingua, 122(3), 303-317 
Ezeizabarrena, M. J., \& Larrañaga, M. P. (1996). Ergativity in Basque: a problem for language acquisition?. Linguistics, 34(5), 955-992

Ezeizabarrena, M. J., Manterola, I., \& Beloki, L. (2009). Euskara H2 goiztiarraren ezaugarrien bila: adizkiak eta gramatika-kasuak haurren ipuinkontaketetan. Euskera, 54, 2-1.

Fenson, L., Dale, P. S., Reznick, J. S., Bates, E., Thal, D. J., Pethick, S. J., ... \& Stiles, J. (1994). Variability in early communicative development. Monographs of the society for research in child development, i-185.

Feys, J. (2016). Nonparametric tests for the interaction in two-way factorial designs using R. The R Journal, 8(1), 367-378.

García, I., Eizabarrena, M. J., Petuya, A., Arratibel, A. B. N., Almgren, M., \& Colina, A. (2007). Euskararen garapena lehen hizkuntza legez eta morfologiaren agerrera mailakatuaren inguruan. UZTARO, 60, 67-87.

Gathercole, V. C. M., \& Thomas, E. M. (2009). Bilingual first-language development: Dominant language takeover, threatened minority language take-up. Bilingualism: Language and Cognition, 12(02), 213-237.

Genesee, F., \& Nicoladis, E. (2007). Bilingual acquisition. In E. Hoff \& M. Schatz (eds.), Handbook of Language Development, 324-342. Oxford, Eng.: Blackwell.

Gibson, T. A., Oller, D. K., Jarmulowicz, L., \& Ethington, C. A. (2012). The receptiveexpressive gap in the vocabulary of young second-language learners: Robustness and possible mechanisms. Bilingualism: Language and Cognition, 15(01), 102116. 
Gibson, T. A., Peña, E. D., \& Bedore, L. M. (2014). The relation between language experience and receptive-expressive semantic gaps in bilingual children. International Journal of Bilingual Education and Bilingualism, 17(1), 90-110.

Gollan, T. H., Montoya, R. I., Cera, C., \& Sandoval, T. C. (2008). More use almost always means a smaller frequency effect: Aging, bilingualism, and the weaker links hypothesis. Journal of memory and language, 58(3), 787-814.

Grüter, T. (2005). Comprehension and production of French object clitics by child second language learners and children with specific language impairment. Applied psycholinguistics, 26(03), 363-391.

Gutiérrez-Clellen, V. F., \& Kreiter, J. (2003). Understanding child bilingual acquisition using parent and teacher reports. Applied Psycholinguistics, 24(2), 267-288.

Hoff, E., Core, C., Place, S., Rumiche, R., Señor, M., \& Parra, M. (2012). Dual language exposure and early bilingual development. Journal of Child Language, $39(1), 1-27$.

Johnson, V. E., de Villiers, J. G., \& Seymour, H. N. (2005). Agreement without understanding? The case of third person singular/s. First Language, 25(3), 317330.

Keller, K., Troesch, L. M., \& Grob, A. (2015). A large receptive-expressive gap in bilingual children. Frontiers in psychology, 6 .

Kohnert, K. (2010). Bilingual children with primary language impairment: Issues, evidence and implications for clinical actions. Journal of Communication Disorders, 43(6), 456-473. 
Kohnert, K., Kan, P. F., \& Conboy, B. T. (2010). Lexical and grammatical associations in sequential bilingual preschoolers. Journal of Speech, Language, and Hearing Research, 53(3), 684-698.

Laka, I., Santesteban, M., Erdocia, K., \& Zawiszewski, A. (2012). The Basque language in the minds of native and non-native bilinguals. The challenge of a bilingual society in the Basque Country, 157-172.

Larrañaga, P. (1994). La evolución del caso en euskera y castellano. In J. Meisel (ed), La adquisición del vasco y del castellano en niños bilingües. Frankfurt am Main, Germany: Vervuert.

Larrañaga, P., \& Guijarro-Fuentes, P. (2012). The acquisition of copula verbs in Basque by bilinguals. International Journal of Bilingualism, 17(3), 284-308.

Legendre, G., Culbertson, J., Zaroukian, E., Hsin, L., Barrière, I., \& Nazzi, T. (2013). Is children's comprehension of subject--verb agreement universally late? Comparative evidence from French, English, and Spanish. Lingua, 144, 21-39

Leonard, L. B. (2014). Specific Language Impairment across languages. Child Development Perspectives, 8(1), 1-5.

Leonard, L. B., Miller, C. A., \& Owen, A. J. (2000). The comprehension of verb agreement morphology by English-speaking children with Specific Language Impairment. Clinical Linguistics \& Phonetics, 14(6), 465-481.

Lesaux, N. K., Crosson, A. C., Kieffer, M. J., \& Pierce, M. (2010). Uneven profiles: Language minority learners' word reading, vocabulary, and reading comprehension skills. Journal of Applied Developmental Psychology, 31(6), 475-483. 
Marchman, V. A., \& Bates, E. (1994). Continuity in lexical and morphological development: A test of the critical mass hypothesis. Journal of Child Language, 21(2), 339-366.

Marchman, V. A., Martínez-Sussman, C. \& Dale, P. S. (2004). The language-specific nature of grammatical development: Evidence from bilingual language learners. Developmental Science, 7(2), 212-224

Matthews, S., \& Yip, V. (2011). Unbalanced bilingual acquisition as a mechanism of grammatical change. Bilingualism: Language and Cognition, 14(02), 159-161.

Meisel, J. M. (2012). Remarks on the acquisition of Basque-Spanish bilingualism. International Journal of Bilingualism, 17(3), 392-399.

Müller, N., \& Hulk, A. (2001). Crosslinguistic influence in bilingual language acquisition: Italian and French as recipient languages. Bilingualism: Language and cognition, 4(1), 1-21.

Munarriz, A., Ezeizabarrena, M. J., \& Gutierrez-Mangado, M. J. (2016). Differential and selective morpho-syntactic impairment in Spanish-Basque bilingual aphasia. Bilingualism: Language and Cognition, 19(04), 810-833.

Nicoladis, E., Rose, A., \& Foursha-Stevenson, C. (2010). Thinking for speaking and cross-linguistic transfer in preschool bilingual children. International Journal of Bilingual Education and Bilingualism, 13(3), 345-370.

Noguchi, K, Latif, M., Karthinathan, T. Konietschke, F., Gel, Y. R., \& Brunner, E. (2012). Nonparametric Analysis of Longitudinal Data in Factorial Experiments. $R$ package version 2.1 .

Oller, D. K., Pearson, B. Z., \& Cobo-Lewis, A. B. (2007). Profile effects in early bilingual language and literacy. Applied Psycholinguistics, 28(2), 191-230. 
Paradis, J., Crago, M., \& Genesee, F. (2005). Domain-specific versus domain-general theories of the deficit in SLI: Object pronoun acquisition by French-English bilingual children. Language Acquisition, 13(1), 33-62.

Paradis, J., \& Jia, R. (2017). Bilingual children's long-term outcomes in English as a second language: language environment factors shape individual differences in catching up with monolinguals. Developmental Science, 20(1).

Parra, M., Hoff, E., \& Core, C. (2011). Relations among language exposure, phonological memory, and language development in Spanish-English bilingually developing 2-year-olds. Journal of Experimental Child Psychology, 108(1), 113-125.

Pearson, B. Z., Fernández, S. C., Lewedeg, V., \& Oller, D. K. (1997). The relation of input factors to lexical learning by bilingual infants. Applied Psycholinguistics, $18(01), 41-58$.

Pearson, B. Z., Fernández, S. C., \& Oller, D. K. (1993). Lexical development in bilingual infants and toddlers: Comparison to monolingual norms. Language learning, 43(1), 93-120.

Pérez-Leroux, A. T. (2005). Number problems in children. In Proceedings of the 2005 Canadian Linguistic Association Annual Conference (Vol. 12, p. 12). London, Canada: University of Western Ontario.

Pickering, M. J., \& Garrod, S. (2014). Neural integration of language production and comprehension. Proceedings of the National Academy of Sciences, 111(43), $15291-15292$.

Pohlert, T. (2016). The Pairwise Multiple Comparison of Mean Ranks Package. $R$ package version 4.3 . 
Pourquié, M. (2013). Verb processing in Basque and French agrammatic aphasia: A “post-lexical access" deficit. Aphasiology, 27(12), 1472-1510.

Pourquié, M. (2015). fLEX: Multilingual assessment of inFlectional and LEXical processing. Software, Intellectual property 2016-01-88, Basque government.

R Development Core Team (2018). R: A language and environment for statistical computing. Vienna, Austria: R Foundation for Statistical Computing. Retrieved from <http://www.r-project.org $>$.

Scherger, A. L. (2016). Kasuserwerb bilingual deutsch-italienischer Kinder: vorübergehend verzögernder Spracheneinfluss. Linguistische Berichte, 246, 197 241

Soto Valle, R., \& Aguado Alonso, G. (2015). Apuntes sobre la adquisición de la morfosintaxis del euskera en niños de 2 y medio a 5 años. Revista de Logopedia, Foniatría y Audiología, 35(1), 30-49.

Swanson, H. L., Rosston, K., Gerber, M., \& Solari, E. (2008). Influence of oral language and phonological awareness on children's bilingual reading. Journal of School Psychology, 46(4), 413-429.

Thordardottir, E., Rothenberg, A., Rivard, M. E., \& Naves, R. (2006). Bilingual assessment: Can overall proficiency be estimated from separate measurement of two languages?. Journal of Multilingual Communication Disorders, 4(1), 1-21.

Unsworth, S. (2013). Assessing the role of current and cumulative exposure in simultaneous bilingual acquisition: The case of Dutch gender. Bilingualism: Language and Cognition, 16(01), 86-110. 
Windsor, J., \& Kohnert, K. (2004). The Search for Common Ground Part I. Lexical Performance by Linguistically Diverse Learners. Journal of Speech, Language, and Hearing Research, 47(4), 877-890.

Yan, S., \& Nicoladis, E. (2009). Finding le mot juste: Differences between bilingual and monolingual children's lexical access in comprehension and production. Bilingualism: Language and Cognition, 12(03), 323-335. 